\title{
Some Heretical Thoughts on Fusion and Climate
}

\author{
Wallace Manheimer ${ }^{1}$
}

Published online: 12 January 2016

(c) The Author(s) 2016. This article is published with open access at Springerlink.com

\begin{abstract}
This article presents and explores three heretical thoughts regarding fusion and climate. First, the only way that fusion can contribute to midcentury power is by switching its goal from pure fusion, to fusion breeding. Doing so could lead to a sustainable, carbon free, environmentally and economically viable, midcentury infrastructure, with little or no proliferation risk, which could provide terawatts of power for the world. Second, while $\mathrm{CO}_{2}$ input to the atmosphere may, at some point, become a concern to the earth's climate, an Internet search shows that there is no evidence that we are anywhere near that point now and likely will not be before midcentury at the earliest. Third, those who insist on a nearly immediate end to $\mathrm{CO}_{2}$ input into the atmosphere, are little different from others who have caused panics at various times in American history. The timing could be serendipitous; the time necessary to develop fusion breeding could well match up to the time when it is needed so as to avoid harm to the earth's climate and/or depletion of finite energy resources.
\end{abstract}

Keywords Fusion breeding - Sustainable midcentury power - Climate alarmism - Heretical thoughts - Prophetic pronouncements $\cdot$ Paris agreement

As the dates for implementation of fusion keep getting pushed back, and as its costs continue to rise; and as the calls to reduce $\mathrm{CO}_{2}$ input in the atmosphere get more and

Wallace Manheimer-Retired from NRL.

This work was not supported by any organization, public or private.

Wallace Manheimer

wallymanheimer@yahoo.com

1 NRL, Allendale, NJ, USA more strident, it is appropriate for this author to go on record expressing some heretical thoughts on both.

In a nutshell, fusion is a potentially vital mid century energy source, but only if its goal is shifted from pure fusion, to fusion breeding. Pure fusion is the use of the $14 \mathrm{MeV}$ neutron's kinetic energy for instance to boil water. Fusion breeding uses this same kinetic energy to boil water, AND what, for want of a better term, we will call the neutron's potential energy to produce $1 / 2-3 / 4$ of a ${ }^{233} \mathrm{U}$ from thorium. However when this is burned in a conventional nuclear reactor, it produces about $100-150 \mathrm{MeV}$, effectively increasing the neutron energy by about an order of magnitude. As a fuel producer, fusion breeding is about an order of magnitude more prolific than fission breeding, its competitor. This order of magnitude increase in fuel productivity is the main reason to embrace fusion breeding, rather than simply settling for fission breeding, which obviously has a much shorter development path. To illustrate, a single fusion breeder can fuel five light water reactors (LWR's) of equal power. It would take two fission breeders, at maximum breeding rate to fuel one.

Pure fusion has receded so far into the future that it cannot be a power source that anyone alive today can see as affecting his or her life. Input of $\mathrm{CO}_{2}$ into the atmosphere may or may not be a long-term problem, but it is not a problem at this point. If fusion breeding can be brought on line by mid-century, the responsible use of fossil fuel until then should cause few if any environmental problems. Furthermore, at this point, fossil fuel is all we have got. The author [1], and many others have made the case that solar power (solar thermal, solar photovoltaic, wind, and biofuel) cannot provide this power in nearly the same quantity, at nearly the same low cost as fossil fuel. This use of fossil fuel has lifted billions out of abject poverty. End fossil fuel use now, or in the next decade or two, this 
worldwide poverty will come roaring back. Hence there is a strong moral case for the use of fossil fuel.

However by midcentury, there could well be a crying need for an additional energy source either for reasons of climate, depletion of a finite resource (i.e. fossil fuel and fissile material) or both. The options are few. This is where fusion breeding could come into play a vital role.

The author has set out the case for fusion breeding in a review article in this journal [2] as well as a summary article in the journal in the special issue on strategic opportunities in fusion [3]. It reviews the progress of both magnetic and inertial fusion. It lays out a potential path for production of midcentury large scale, economical, carbon free, environmentally sound, power production with little or no proliferation risk. It is based on an ITER like tokamak fusion device, or a NIF like laser fusion device. The key to this ability to generate mid century power is that the demands on the fusion reactor, whatever it is, are greatly reduced for fusion breeding as opposed to pure fusion. Of course this assumes ITER will work as designed and/or NIF somehow achieves success. The review article also shows that the path to pure fusion, is much more arduous and would take many more decades of development, assuming it can be done at all.

By comparing the status of various magnetic fusion devices, it argues that almost certainly the tokamak is the only way to go, although it does admit that the stellarator may a possible alternative. Right now it is far behind the tokamak as regards several important metrics, but it will be very interesting to see what the Germans accomplish as they bring their Wendelstein [7] stellarator on line. While it is always possible that a genius can invent a fusion device in his or her garage, the review article expresses skepticism as to whether supporting fusion by venture capital [4], which is all the rage these days is a viable approach. Does the private sector really have the billions of dollars, and patience for the decades it will take, to develop such a speculative concept? If so, this author can only wish them luck.

Fusion breeding envisions a sustainable, economical, environmentally sound, proliferation resistant, carbon free energy structure which can provide the world with hundreds of gigawatts or terawatts by midcentury. It is called 'The Energy Park'. In it there is one fusion reactor fueling five LWR's. As the wastes from these are discharged every year, the transuranic elements (i.e. those with proliferation risk) are separated out and burned in a single fast neutron reactor of about equal power, for instance the integral fast reactor (IFR), which has been developed at the Argonne National Lab. The British are building a much more powerful version now with the specific purpose of treating their large plutonium stockpile. If a more advanced thermal nuclear reactor is used instead of an LWR, the requirements on the fusion reactor and IFR in the energy park could be relaxed. In the energy park, there is neither long-term storage, nor long distance travel of any material with proliferation potential, it is all destroyed in the park. Only thorium comes in, only about $7 \mathrm{GW}$ electric power, and/or manufactured liquid fuel, goes out.

It is entirely possible that the world could build several hundred to a thousand energy parks by midcentury. All except the fusion breeder exist now or are being actively developed. Several energy parks, but without the fusion breeder and actinide burner exist now in Canada and Japan. However currently this is neither a sustainable, nor an environmentally sound energy infrastructure. The supply of fissile material is limited to less than $1 \%$ of the potential energy resource, and the actinide wastes build up. The fusion breeder would solve the first problem; the IFR, the second.

Now let us consider climate change. As this is being written, the heretical nature this article just got much more heretical. On 12 Dec 2015, the UN meeting in Paris resulted in an agreement signed by 186 nations. Here is a link to the agreement: http://unfccc.int/resource/docs/2015/ cop21/eng/109.pdf.

Among other things, the agreement states: "Also recognizing that deep reductions in global emissions will be required in order to achieve the ultimate objective of the Convention and emphasizing the need for urgency in addressing climate change." Notice that the agreement gives no recognition to the role fossil fuel has played in advancing modern civilization; 'global emissions' instead are portrayed as something more like smoking, something one can just quit. There is no recognition of the fact that without fossil fuel, or a different energy source available at about the same quantity and price, the world will sink back into abject poverty, for all but the privileged few, as had been humanity's fate for most of its existence. No recognition that even if their assessment of the climate threat is correct, there are competing priorities. No recognition that these competing priorities would have to be balanced in some way. No recognition that it is extremely unlikely that what it calls sustainable power (solar thermal, solar photovoltaic, wind and biofuel) can come anywhere near filling the void the agreement is attempting to create. No recognition of the wisdom of Richard Feynman when he said regarding the Challenger disaster: "For a successful technology reality must take precedence over public relations, for nature cannot be fooled."

But still, how can one possibly dispute such worldwide unanimity? The only way is by presenting actual data. Nobody disputes that the earth's climate has been changing for billions of years and will continue to do so with or without human intervention. The key question is whether human burning of fossil fuel is causing a climate shift, 
which could be harmful. There is a scientific consensus that the burning of fossil fuel is causing a buildup of atmospheric $\mathrm{CO}_{2}$, which nobody disputes. The other assertion is that this buildup is causing irreparable damage to the earth's atmosphere and ecosystems. The mainstream media (NY Times, Washington Post, NBC and CBS News....) is a vast echo chamber, summarily brushing aside every opposing point of view like so much dust. Believers claim that $97 \%$ of scientists agree with them. Does the scientific community really support this position with such unanimity? There is at least one group of very eminent scientists who claim that not only does $\mathrm{CO}_{2}$ in the atmosphere do no harm, it is beneficial [5]. Also there is a group of about 32,000 scientists who signed a petition disputing man made climate change. Frederick Seitz, a former president of the American National Academy of Science, obviously an extremely qualified scientist, led the petition drive. Here is a link to their petition (http://www.petitionproject.org). If $97 \%$ of scientists truly believe in man made climate change, this means that whoever produced this statistic, somehow polled about a million other scientists (likely there are not even that many), all of whom believe. In this author's opinion, the reluctance of the mainstream press to further investigate the validity of these claims of scientific unanimity is one of the greatest examples of journalistic irresponsibility and dereliction of duty he has ever seen.

Despite the large number of scientists signing the petition, another issue is whether a scientist has to toe the line to protect his funding. This author personally knows of one extremely capable scientist at a major Ivy League university, a skeptic of human induced global warming (https://paw.princeton.edu/issues/2010/03/17/pages/7940/ index.xml) whose grant was suddenly canceled, for whatever reason (http://www.nature.com/news/trailblazing-can cer-physics-project-accused-of-losing-ambition-1.18122). Green, like oil and coal, is big business now, with lots of very powerful, well-funded interests protecting it, and attacking its opponents.

It is undeniable that atmospheric $\mathrm{CO}_{2}$ is a vital nutrient for plants; without it, life on earth would not be possible. Just what is the optimum level for $\mathrm{CO}_{2}$ in the atmosphere anyway? It is certainly not zero. The UN statement gives no indication of what this is. Is the preindustrial level perfect? Over the past 500 million years, the $\mathrm{CO}_{2}$ level has varied from over 5000 parts per million, to the preindustrial level of 280, and life (but not human life) on earth thrived all during this time [5].

Furthermore, are these loudly announced claims of imminent gloom and doom correct or believable? Without getting into the detailed science of the earth's atmosphere, which is extremely complicated, it is possible to examine some of the claims of those the author will call alarmists, and check them out against available data. This information is of extreme importance. Civilization depends heavily on the use of fossil fuel, much more so than the UN agreement admits. If this is causing an immediate or imminent threat to the earth's atmosphere, obviously something must be done. If the data does not bear out the fears of the alarmists, then at least the world has plenty of time to react; also it could be possible that nothing at all needs to be done about $\mathrm{CO}_{2}$ in the atmosphere [5].

With the advent of the Internet, one can easily check out these claims by doing a Google (or other search engine) search. Manheimer Refs. [6 and 7] do just that. They lists the claims of several of the alarmists, and checks them out. There is a tremendous amount of information available at the click of a button. This author used a Google, and mostly Google images search. This data is not at all controversial; it has no political agenda (i.e. there are many charts available, all about the same). This information is used to check out these claims of gloom and doom. Anyone can easily do this and check for himself. The data presented in Manheimer Refs. [6 and 7] indicate that these claims are either wildly exaggerated, or else concern processes that have been occurring at about the same rate since long before $\mathrm{CO}_{2}$ in the atmosphere increased. Again, the failure of the mainstream media to perform this same, simple investigation will tarnish its reputation for decades to come.

Several readers of Manheimer Ref. [6] have criticized the use of Google to make the point. They asserted that the only way someone can check the data is by reading and absorbing all or most of the original papers, thousands of them. This criticism is without merit. It is not as if I used a Google search to find a subtle, controversial aspect of the radiative properties of clouds with particular impurities, or the nonlinear behavior of Rossby waves in the upper atmosphere. The searches were more like 'price of a kilowatt hour in Germany', or 'world agricultural production', where the data is noncontroversial and has no political agenda. Alarmists have made specific assertions about things like this, and a Google search is a perfectly acceptable way to check them out.

The UN statement does explicitly state that the goal is to keep the world temperature rise below 2, or preferably $1.5{ }^{\circ} \mathrm{C}$ above the preindustrial level. "Emphasizing with serious concern the urgent need to address the significant gap between the aggregate effect of Parties' mitigation pledges in terms of global annual emissions of greenhouse gases by 2020 and aggregate emission pathways consistent with holding the increase in the global average temperature to well below $2{ }^{\circ} \mathrm{C}$ above pre-industrial levels and pursuing efforts to limit the temperature increase to $1.5^{\circ} \mathrm{C} . . . "$. This, of course assumes there is a causal, well-understood relation between global use of fossil fuels and an exact global temperature rise. But is there such an understanding? Or is it all wishful thinking? 
Also, there are all sorts of articles in the media of calamities of rising sea levels and intense storms if the temperature rises by even this $1.5^{\circ} \mathrm{C}$; as if this were established, undeniable fact. Perhaps, but measurements up to now, indicate no sign of any imminent calamity, and the temperature has already risen $1{ }^{\circ} \mathrm{C}$ above the preindustrial level. The seas have been rising at $20 \mathrm{~cm}$ per century for decades. Glaciers have been receding at about the same rate for centuries. Storm intensities have been slowly decreasing over the last century or so. There has been no steady increase in forest fires or droughts. Agricultural production has been increasing. Data confirming all of this is readily available, Refs. [6 and 7] present some of it and shows how anyone can check it out.

Will another half degree really be calamitous? Will it cause oceans to suddenly rise the 4-6 meters necessary to submerge many low lying islands by the end of the century, as many in Paris state with such absolute certainty? This would mean an increase in the ocean's rate of rise by about a factor of 25(!) in just a few years. All of this is theory; there is no data to back it up. This theory assumes that another halfdegree rise in temperature will suddenly cause a gigantic change in the earth's sea level and ecosystems, while the one-degree rise over the previous century has caused none. The consequences of enacting the treaty are major for human civilization, lifestyle, health and prosperity. Is it really necessary, or are the alarmists shouting "FIRE" in a crowded theater? Is it worth changing the lifestyle of billions, forcing most of the world back into abject poverty because of these theories, which have little or no data confirming them? That is a question for our political leaders. At this point, the indication is that this is the political will. It remains to be seen how long this lasts once the costs become more and more apparent, as Manheimer Refs. [6 and 7] show. Furthermore, the Paris agreement is only a statement of intent; there is no enforcement mechanism. It remains to be seen if fossil fuel use does get reduced, especially in the developing world, in India, Nigeria, Mexico, Indonesia....

Manheimer Ref. [8] gets more speculative and attempts to analyze the historical context of the calls to end $\mathrm{CO}_{2}$ in the atmosphere immediately or very soon. It places these in the context of other panics in American history. Namely it is treated as a planetary emergency by some, because of a new set of at modern day 'prophets' who demand action, claiming they alone have access to knowledge that ordinary people cannot have (and cannot confirm with a Google search). This paper compares these global warming arguments to two other important events in American history, the Salem witchcraft trials, and the prosecution of preschool teachers for child sexual abuse. Another case, which could fit into this mold, is the McCarthy era in the United States in the 1950s although this is not discussed in Manheimer Ref. [8]. It argues that in all cases, a belief in human sin, this sin only discerned by modern day 'prophets', motivates all three arguments. It argues that this is a recurring aspect of American history, and that the most extreme calls to end fossil fuel use nearly immediately are another example. Just like with all the other false prophets, this can lead to panicked action, which can be extraordinarily harmful.

To summarize, the three heretical thoughts expressed here are:

1. For fusion to have a significant impact on mid century power requirements, when it may well be urgently needed, the only option is to switch from pure fusion, to fusion breeding. 'The Energy Park' could become an achievable, sustainable, economical, carbon free, environmentally sound midcentury energy infrastructure, which could provide terawatts of power to the world. A further discussion is available in Manheimer Ref. [2], which is available open access.

2. As opposed to anecdotal evidence of this or that storm, this or that numerical simulation, or this or that theory that the seas will rise $5 \mathrm{~m}$; the actual data up to now show that fears of imminent climate catastrophe are either wildly overstated, or else involve processes occurring since long before excess $\mathrm{CO}_{2}$ in the atmosphere became a concern. But based on actual measurements and reasonable extrapolation of them, there is no reason why the responsible use of fossil fuel cannot support worldwide civilization up through midcentury when hopefully fusion breeding will take over. The argument to greatly restrict fossil fuel rests entirely on the theoretical assertion that there will be a sudden and dramatic change in the very nature of the data at some point in the near future. But are these theoretical assertions, which are not backed up by any measured data, sufficient to greatly upset the lifestyle of billions of people, and to further impoverish the already most impoverished parts of the world? A further discussion is available in Manheimer Refs. [6 and 7], which are available open access.

3. The most emphatic advocates of an immediate or imminent end of $\mathrm{CO}_{2}$ input into the atmosphere share a great deal with biblical prophets, who could see human sin where no one else could, and insisted on major changes in human behavior. However unlike their biblical predecessors, these modern day prophets have no direct pipeline to God and are almost always 'false prophets'. A further discussion is available in Manheimer Ref. [8], which is available open access.

As far as the author is concerned, there is no way any reasonable person can dispute heretical thoughts numbers 1 and 2. Regarding number 3 , it gets into motive, psychology, even theology, and is obviously more speculative. However it seems to me that it is a case somebody ought to make, and I seem to be that someone. 
The upshot is that fusion, but only fusion breeding, and only if intelligently supported, can develop into an important power source for mid century. The world will very likely need it by then; the fusion community can very likely deliver it by then. Until then, the world can continue to responsibly use fossil fuel with little danger to the environment.

Open Access This article is distributed under the terms of the Creative Commons Attribution 4.0 International License (http://creative commons.org/licenses/by/4.0/), which permits unrestricted use, distribution, and reproduction in any medium, provided you give appropriate credit to the original author(s) and the source, provide a link to the Creative Commons license, and indicate if changes were made.

\section{References}

1. W. Manheimer, American physics, climate change and energy, physics and society, http://www.aps.org/units/fps/newsletters/ 201204/manheimer.cfm. Accessed 2 Apr 2012
2. W. Manheimer, Fusion breeding for mid-century sustainable power. J. Fusion Energ. 33(3), 199-234 (2014). doi:10.1007/ s10894-014-9690-9

3. W. Manheimer, Fusion breeding, and old, new strategic opportunity for fusion. J. Fusion Energ. (2015). doi:10.1007/s10894-0159998-0

4. Cover story on venture capital support of various fusion schemes, Time Magazine 186(18), 2 Nov 2015

5. $\mathrm{CO}_{2}$ Coalition.org (a coalition of eminent scientists who believe $\mathrm{CO}_{2}$ in the atmosphere is not only not harmful, but is beneficial)

6. W. Manheimer, What do alarmists say about climate change? What does Google say? Stand Sci. Res. Essays 3(11), 309-325 (2015)

7. W. Manheimer, A simple way to check on assertions of damage from climate change. Int. J. Eng. Appl. Sci. 2(12), 59-69 (2015)

8. W. Manheimer, Original sin, prophets, witches, preschool sex abuse, and global warming. Stand. Sci. Res. Essays 3(9), 277-289 (2015) 